\title{
Long non-coding RNA miR155HG silencing restrains ovarian cancer progression by targeting the microRNA-155-5p/tyrosinase-related protein 1 axis
}

\author{
AIPING WEN ${ }^{1,2^{*}}$, LE LUO $^{3 *}$, CHENGCHAO DU $^{1}$ and XIN LUO ${ }^{2}$ \\ ${ }^{1}$ Department of Gynecology and Obstetrics, Affiliated Hospital of North Sichuan Medical College, Nanchong, \\ Sichuan 637000; ${ }^{2}$ Department of Gynecology and Obstetrics, The First Affiliated Hospital of Jinan University, \\ Guangzhou, Guangdong 510630; ${ }^{3}$ Sichuan Key Laboratory of Medical Imaging, Affiliated Hospital of \\ North Sichuan Medical College, Nanchong, Sichuan 637000, P.R. China
}

Received December 7, 2020; Accepted June 22, 2021

DOI: $10.3892 /$ etm.2021.10672

\begin{abstract}
Ovarian cancer (OC) is the third commonest gynecological malignancy worldwide. The long non-coding (lnc)RNA microRNA (miR)155HG functions as an oncogene in different human cancers. However, the function and molecular mechanism of miR $155 \mathrm{HG}$ in OC remain elusive. The present study indicated that the expression levels of miR155HG and tyrosinase-related protein 1 (TYRP1) were significantly increased, whereas that of miR $155-5 p$ was decreased in OC tissues and cells, as detected by real-time quantitative polymerase chain reaction. It was demonstrated that knockdown of miR155HG markedly inhibited OC cell viability, migration and invasion while promoting apoptosis, as indicated by 3-(4,5-dimethylthiazol-2-yl)-2,5-diphenyltetrazolium bromide, wound healing, Transwell and western blot assays. Mechanistically, it was revealed that miR155HG and TYRP1 were both targeted by miR-155-5p with complementary binding sites in the $3^{\prime}$ untranslated region. A dual-luciferase reporter assay was used to confirm the targeting relationship between miR155HG, miR-155-5p and TYRP1. In addition, the interaction between miR155HG and miR-155-5p was further demonstrated by radioimmunoprecipitation and pull-down assays. In addition, feedback approaches determined that miR-155-5p inhibition or TYRP1 overexpression markedly reversed the inhibitory effects of miR155HG knockdown on OC cell viability, migration and invasion as well as
\end{abstract}

Correspondence to: Dr Xin Luo, Department of Gynecology and Obstetrics, The First Affiliated Hospital of Jinan University, 613 West Huangpu Avenue, Tianhe, Guangzhou, Guangdong 510630, P.R. China

E-mail: doctorapw@163.com

*Contributed equally

Key words: ovarian cancer, long non-coding RNA miR155HG, microRNA-155-5p, tyrosinase-related protein 1, migration, invasion weakened the promotive effect of miR155HG knockdown on OC cell apoptosis. Thus, miR155HG silencing inhibited the malignant biological behavior of OC cells by targeting the miR-155-5p/TYRP1 axis. The present study provides novel insights into the underlying mechanism of OC progression.

\section{Introduction}

Ovarian cancer (OC) is the third commonest gynecological malignancy worldwide (1). Patients are frequently diagnosed with $\mathrm{OC}$ at an advanced stage and the 5-year survival rate is only $35 \%$ (2). Despite advances in chemotherapy and surgery, the prognosis of patients with OC remains unsatisfactory (3). High recurrence rates and poor outcomes due to OC metastasis pose serious challenges (4). Therefore, it is necessary to explore the molecular mechanisms of OC progression to discover new therapeutic strategies.

Long non-coding (lnc) RNAs serve multiple roles in the occurrence and development of OC. LncRNA PVT1 regulates EZH2 to downregulate microRNA (miRNA/miR)-214, resulting in the suppression of OC progression (5). LncRNA LINC00319 contributes to OC progression by inhibiting miR-423-5p and enhancing nucleus accumbens-associated 1 expression (6). LncRNA PCAT6 restrains PTEN expression to accelerate the initiation and progression of $\mathrm{OC}(7)$. Numerous studies have shown that lncRNA miR155HG (miR155HG) serves critical roles in diverse tumors (8-10). miR155HG promotes pancreatic cancer cell growth and inhibits apoptosis by suppressing miR-802 expression (8). miR155HG deficiency attenuates glioblastoma tumorigenesis by downregulating Annexin A2 expression via an increase in miR-185 expression (9). Notably, the expression of miR155HG is enhanced in OC tissues and cells (10).

miRNAs have been shown to participate in different gynecological malignancies, including OC. miR-126-3p modulates PLXNB2 expression to attenuate OC progression (11). miR-603 suppresses the malignancy of OC cells by targeting hexokinase-2 (12). miR-122 inhibits OC cell growth by repressing prolyl 4-hydroxylase subunit $\alpha 1$ (13). miR-155-5p has been regarded as a pivotal regulator of multiple 
cancers. miR-155-5p elevation impedes gastric cancer cell proliferation and triggers apoptosis (14). miR-155-5p regulates IGF2 through the PI3K pathway to exert tumor-repressing roles in Wilms tumors (15). Notably, miR-155-5p reduces OC cell viability by inhibiting HIFl $\alpha$ (16).

Tyrosinase-related protein (TYRP) 1 is a melanogenic enzyme and protein (17). Previous research has reported on the relationship between melanogenic proteins and cancers, such as TYRP1 in breast cancer (18) and TYRP2 in retinoblastoma (19). TYRP1 exerts tumor-promoting functions in different types of cancer. Increased TYRP1 expression in lymph node metastases from melanoma patients is related to unfavorable prognosis (20). TYRP1 has emerged as an oncogene in colon cancer and high levels of TYRP1 are associated with decreased overall survival rates (21). Notably, El Hajj et al (22) reported that TYRP1 is a target of miR-155.

Despite the aforementioned studies, the molecular mechanisms of miR155HG, miR-155-5p and TYRP1 in OC progression remain unclear. The present study assessed the expression and roles of miR155HG in OC. In addition, the relationships between miR155HG, miR-155-5p and TYRP1 in OC were determined. The present study aimed to reveal the molecular mechanism of miR155HG in OC cell viability, migration, invasion and apoptosis.

\section{Materials and methods}

Ethics statement. The study was approved by the ethics committee of the Affiliated Hospital of North Sichuan Medical College [approval no. 2020ER (A) 066)]. Written informed consent was obtained from all participants. The study was conducted in accordance with the principles of the Declaration of Helsinki.

Clinical samples. Patients with OC $(\mathrm{n}=55)$ who underwent ovariectomy between September 2017 and October 2019 at the Affiliated Hospital of North Sichuan Medical College (Nanchong, China) were enrolled in this study. Among them, 41 cases were the serous subtype, 8 cases were the endometrioid subtype and 6 cases were other subtypes. The histopathological diagnosis of the cases was in accordance with the diagnostic categories of the World Health Organization 2020 (23). OC tissues ( $\mathrm{n}=55$; tumor group) and paired adjacent non-tumor tissues (tissue which were $1-2 \mathrm{~cm}$ away from the tumor tissues; adjacent group) were obtained the from patients with $\mathrm{OC}$ who underwent ovariectomy. Prior to ovariectomy, radiotherapy or chemotherapy was not administered to the patients.

Cell culture. The OVCAR3 and SK-OV-3 OC cell lines and normal IOSE80 ovarian cell line (Chinese Academy of Sciences) were cultured in Roswell Park Memorial Institute (RPMI)-1640 medium (Invitrogen; Thermo Fisher Scientific, Inc.) supplemented with $10 \%$ exosome-free fetal bovine serum (FBS; Invitrogen; Thermo Fisher Scientific, Inc.) at $37^{\circ} \mathrm{C}$ with $5 \% \mathrm{CO}_{2}$.

Cell transfection. For cell transfection, OVCAR3 and SK-OV-3 cells grown to $85 \%$ confluence were transfected with $100 \mathrm{nM}$ of negative control (NC) small interfering (si)
RNA (si-NC; 5'-UUCUCCGAACGUGUCACGU-3'), $100 \mathrm{nM}$ of miR155HG siRNA (si-miR155HG-1; 5'-CUGGGAUGU UCAACCUUAA-3'; si-miR155HG-2; 5'-UCUUAAAGGGAA ACUGAAA-3'), $100 \mathrm{nM}$ of mimics NC (5'-UCACAACCU CCUAGAAAGAGUAGA-3'), $100 \mathrm{nM}$ of miR-155-5p mimics (5'-UUAAUGCUAAUCGUCAUAGGGGU-3'), $100 \mathrm{nM}$ of inhibitor NC (5'-CAGUACUUUUGUGUAGUACAA-3'), $100 \mathrm{nM}$ of miR-155-5p inhibitor (5'-ACCCCUAUCACGAUU AGCAUUAA-3'), $1 \mu \mathrm{g}$ of empty plasmid (pcDNA3.1-NC) and $1 \mu \mathrm{g}$ of TYRP1 overexpression plasmid (pcDNA3.1-TYRP1), or co-transfected with $100 \mathrm{nM}$ of si-miR155HG-1 and miR-155-5p inhibitor, $100 \mathrm{nM}$ of si-miR155HG-1 and $1 \mu \mathrm{g}$ of pcDNA3.1-TYRP1 using Lipofectamine ${ }^{\circledR} 3000$ reagent (Invitrogen; Thermo Fisher Scientific, Inc.) for $6 \mathrm{~h}$ at $37^{\circ} \mathrm{C}$. All oligonucleotides or plasmids were purchased from Shanghai GenePharma Co., Ltd. At $48 \mathrm{~h}$ post-transfection, the cells were harvested and reverse transcription-quantitative (RT-q) PCR was conducted to determine the transfection efficiency.

$R T-q P C R$. RT-qPCR procedures were performed according to the corresponding manufacturer's protocols. In brief, total RNA was extracted from tissues and cells using TRIzol ${ }^{\circledR}$ reagent (Thermo Fisher Scientific, Inc.). RNA was reverse transcribed into complementary DNA using the Prime Script RT reagent kit (Takara Biotechnology Co., Ltd.). The SYBR-Green PCR kit (Takara Biotechnology Co., Ltd.) and TaqMan MicroRNA Assay Kit (Applied Biosystems; Thermo Fisher Scientific, Inc.) were used for qPCR analysis. The following thermocycling conditions were used for the qPCR: Initial denaturation at $95^{\circ} \mathrm{C}$ for $3 \mathrm{~min}$; followed by 40 cycles at $95^{\circ} \mathrm{C}$ for $15 \mathrm{sec}$, annealing at $60^{\circ} \mathrm{C}$ for $30 \mathrm{sec}$, elongation at $72^{\circ} \mathrm{C}$ for $1 \mathrm{~min}$; and a final extension at $72^{\circ} \mathrm{C}$ for $5 \mathrm{~min}$. GAPDH, U6 and $\beta$-actin were used for the normalization of miR155HG, miR-155-5p and TYRP1, respectively $(8,24,25)$. Relative expression was calculated using the $2^{-\Delta \Delta \mathrm{Cq}}$ method (26). The primers used are presented in Table I.

Western blot analysis. The transfected OVCAR3 and/or SK-OV-3 cells were lysed with RIPA buffer (Beyotime Institute of Biotechnology) to extract total protein. The protein concentration was detected via the BCA Protein Assay kit. Subsequently, a total of $50 \mu \mathrm{g}$ protein/lane was separated by $10 \%$ SDS-PAGE and then transferred onto PVDF membranes. Following blocking with $5 \%$ skimmed milk for $2 \mathrm{~h}$ at $25^{\circ} \mathrm{C}$, the membranes were incubated overnight at $4^{\circ} \mathrm{C}$ with primary antibodies, including anti-TYRP1 (1:1,000; ab235447; Abcam), anti-Bax (1:1,000; ab32503; Abcam), anti-Bcl-2 $(1: 2,000 ;$ ab182858; Abcam) and anti- $\beta$-actin $(1: 1,000$; ab265588; Abcam). Thereafter, the membranes were incubated with horseradish peroxidase-conjugated secondary antibodies (1:5,000; ab97080; Abcam) at $25^{\circ} \mathrm{C}$ for $1 \mathrm{~h}$. The proteins bound by their respective antibodies on the immunoblots were measured using an enhanced ECL kit (Thermo Fisher Scientific, Inc.) and quantified using ImageLab software (version 2.3; Bio-Rad Laboratories, Inc.).

3-(4,5-dimethylthiazol-2-yl)-2,5-diphenyltetrazolium bromide (MTT) assay. OVCAR3 and SK-OV-3 cells ( $2 \times 10^{3} /$ well) were seeded into 96 -well plates and incubated at $37^{\circ} \mathrm{C}$ with $5 \% \mathrm{CO}_{2}$. At each time point $(0,24,48$ and $72 \mathrm{~h}$ post-transfection), cell 
Table I. Primers sequences.

\begin{tabular}{ll}
\hline Name of primer & \multicolumn{1}{c}{ Sequences (5'-3') } \\
\hline miR155HG-F & CCCAAATCTAGGTTCAAGTTC \\
miR155HG-R & CATCTAAGCCTCACAACAAC \\
GAPDH-F & AGGTGAAGGTCGGAGTCAACG \\
GAPDH-R & AGGGGTCATTGATGGCAACA \\
miR-155-5p-F & GTGCAGGGTCCGAGGTATT \\
miR-155-5p-R & GCCGCTTAATGCTAATCGTGATAG \\
U6-F & GCTTCGGCAGCACATATACTAAAAT \\
U6-R & CGCTTCACGAATTTGCGTGTCAT \\
TYRP1-F & GCTCAGTGCTTGGAAGTTGGT \\
TYRP1-R & AGTTTGTCCTCCAGTTCCGTTTAG \\
$\beta$-actin-F & GACCCTGCCATCTGTGC \\
$\beta$-actin-R & CGGGTGGAGGAGTTTCA
\end{tabular}

miR, microRNA; F, forward; R, reverse.

viability was determined using the MTT cell viability assay kit (Sigma-Aldrich; Merck KGaA) under an inverted light microscope (magnification x400; Olympus Corporation).

Wound healing assay. OVCAR3 and SK-OV-3 cells (1x10\%/well) were incubated in 6-well plates. The cell monolayer was then wounded with a $10-\mu 1$ pipette tip and cultured in serum-free medium. Images of the different stages of wound healing were captured by a light microscopy (magnification, x400; Olympus Corporation) at 0 and $48 \mathrm{~h}$.

Invasion assay. Transwell chambers (24-well; $8 \mu \mathrm{M}$ pore size; BD Biosciences) coated with Matrigel at $37^{\circ} \mathrm{C}$ for $30 \mathrm{~min}$ (BD Biosciences) were used to evaluate cell invasion. OVCAR3 and SK-OV-3 cells $\left(1 \times 10^{5}\right)$ were seeded into the upper chamber of Transwell plates (Corning, Inc.) in serum-free RPMI-1640 medium. Exosome-free FBS (10\%) RPMI-1640 medium was added to the lower chamber of the Transwell plates. After $24 \mathrm{~h}$, cells that had invaded the pores were fixed with methanol and stained with $0.5 \%$ crystal purple at $37^{\circ} \mathrm{C}$ for $30 \mathrm{~min}$. Stained cells were imaged using an inverted light microscope (magnification, x400; Olympus Corporation).

Dual-luciferase reporter assay. The putative binding sites of miR-155-5p on miR155HG and the TYRP1 3' untranslated region (UTR) were predicted using StarBase (version 2.0; http://starbase.sysu.edu.cn) and TargetScan (release 7.2; http://www.targetscan.org/vert_72/), respectively. miR155HG and TYRP1 sequences were generated with wild-type (WT) or mutant miR-155-5p binding sites and cloned them into pmirGLO vectors (Shaanxi Youbio Technology Co., Ltd.). OVCAR3 and SK-OV-3 cells were co-transfected with the luciferase vectors and $\mathrm{NC}$ mimics or miR-155-5p mimics using Lipofectamine ${ }^{\circledR} 3000$ (Invitrogen; Thermo Fisher Scientific, Inc.) for $48 \mathrm{~h}$ at $37^{\circ} \mathrm{C}$. Relative luciferase activity was examined using a dual-luciferase reporter assay system (Promega Corporation). The activity of firefly luciferase was normalized to that of Renilla luciferase.
Statistical analysis. All statistical analyses were performed using GraphPad Prism 8.0 software (GraphPad Software, Inc.). Data are expressed as means \pm standard deviations. The miR155HG, miR-155-5p and TYRP1 expression of OC tissues and paired adjacent non-tumor tissues were assessed using paired Student's t-test. In addition, differences between two groups were analyzed using unpaired Student's t-test. Differences among multiple groups were assessed by a one-way analysis of variance followed by Tukey's post-hoc test. In the analysis of clinicopathological features, the age, diameter, lymph node metastasis, International Federation of Gynecology and Obstetrics (FIGO) stage (27) and histological grade were analyzed using the $\chi^{2}$ test. The pathological subtype was analyzed using the Fisher's exact test. The significance of the correlations was determined using Pearson's correlation analysis. All experiments were performed in triplicate, and each experiment was repeated three times. $\mathrm{P}<0.05$ was considered to indicate a statistically significant difference.

\section{Results}

miR155HG is upregulated in OC. To confirm whether miR155HG is differentially expressed in OC tissues, miR155HG expression was analyzed by RT-qPCR in 55 patients with OC. The results showed that miR155HG expression was considerably upregulated in OC tissues compared with that in adjacent non-tumor tissues ( $\mathrm{P}<0.001$; Fig. 1A). Additionally, miR155HG expression was notably elevated in tumors at FIGO stage III/IV (P<0.01; Fig. 1B). Furthermore, miR155HG expression was clearly enhanced in OVCAR3 and SK-OV-3 cells compared with that in IOSE80 cells $(\mathrm{P}<0.001$; Fig. 1C). According to the analysis of clinicopathological features shown in Table II, the expression of miR155HG was not correlated with age, pathological subtype, diameter and lymph node metastasis $(\mathrm{P}>0.05)$ but was closely associated with the FIGO stage $(\mathrm{P}<0.05)$ and histological grade $(\mathrm{P}<0.01)$ of patients with OC. Notably, the number of patients with OC with high miR155HG expression was greater than the number of patients with OC with low miR155HG expression in the 'low-grade' (grade G3) type of OC $(\mathrm{P}<0.01)$.

miR155HG silencing restrains $O C$ cell viability, migration and invasion while promoting apoptosis. Loss-of-function experiments were performed to investigate whether miR155HG knockdown affects OC progression in vitro. Fig. $2 \mathrm{~A}$ shows that miR155HG was effectively silenced following si-miR 155HG-1 $(\mathrm{P}<0.001)$ and si-miR155HG-2 $(\mathrm{P}<0.01)$ transfection in OVCAR3 and SK-OV-3 cells. Si-miR155HG-1 was used for subsequent assays because of its high silencing efficiency. The MTT assay revealed that the viability of OVCAR3 and SK-OV-3 cells was markedly reduced after si-miR155HG-1 transfection $(\mathrm{P}<0.01$; Fig. $2 \mathrm{~B})$. The wound healing and invasion assays revealed that the migration and invasion of OVCAR3 and SK-OV-3 cells were visibly suppressed by miR155HG deficiency ( $\mathrm{P}<0.001$; Fig. $2 \mathrm{C}$ and $\mathrm{D})$. Bax and Bcl-2 are biomarkers of apoptosis. miR155HG silencing markedly increased the Bax protein expression level and decreased the Bcl-2 protein expression level in OVCAR3 and SK-OV-3 cells $(\mathrm{P}<0.05$; Fig. 2E). 
Table II. Correlation between miR155HG expression and clinicopathological features in ovarian cancer patients.

\begin{tabular}{|c|c|c|c|c|}
\hline Characteristics & $\mathrm{n}$ & miR155HG (Low) 27 & miR155HG (High) 28 & P-value \\
\hline Age & & & & $0.698^{\mathrm{a}}$ \\
\hline$<55$ years & 23 & 12 & 11 & \\
\hline$\geq 55$ years & 32 & 15 & 17 & \\
\hline Pathological subtype & & & & $0.749^{\mathrm{a}}$ \\
\hline Serous & 41 & 19 & 22 & \\
\hline Endometrioid & 8 & 5 & 3 & \\
\hline Others & 6 & 3 & 3 & \\
\hline Diameter & & & & $0.891^{\mathrm{a}}$ \\
\hline$<5 \mathrm{~cm}$ & 27 & 13 & 14 & \\
\hline$\geq 5 \mathrm{~cm}$ & 28 & 14 & 14 & \\
\hline Lymph node metastasis & & & & $0.341^{\mathrm{a}}$ \\
\hline No & 29 & 16 & 13 & \\
\hline Yes & 26 & 11 & 15 & \\
\hline FIGO stage & & & & $0.022^{\mathrm{b}}$ \\
\hline $\mathrm{I}+\mathrm{II}$ & 24 & 16 & 8 & \\
\hline $\mathrm{III}+\mathrm{IV}$ & 31 & 11 & 20 & \\
\hline Histological grade & & & & $0.004^{\mathrm{c}}$ \\
\hline G1-G2 & 25 & 15 & 10 & \\
\hline G3 & 30 & 12 & 18 & \\
\hline
\end{tabular}

${ }^{\mathrm{a}}$ Not significant; ${ }^{\mathrm{b}} \mathrm{P}<0.05 ;{ }^{\mathrm{c}} \mathrm{P}<0.01$. FIGO, Federation International of Gynecology and Obstetrics.
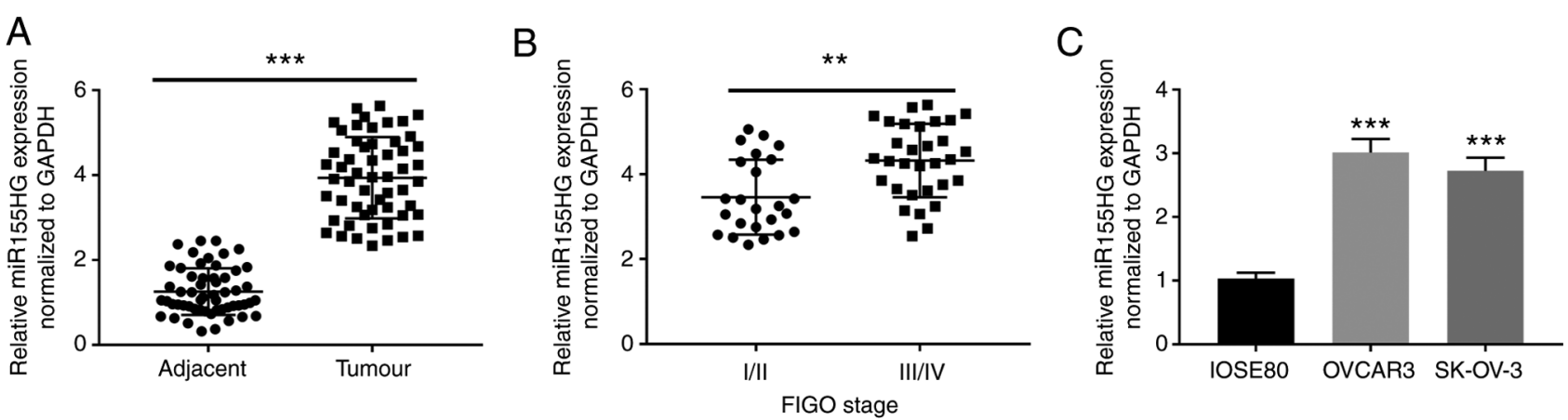

Figure 1. miR155HG is upregulated in OC. (A) The expression of miR155HG in OC tissues and adjacent non-tumor tissues was measured by RT-qPCR. ${ }^{* * * *} \mathrm{P}<0.001$ vs. Adjacent; (B) Relative expression of miR155HG in patients with OC at the FIGO stage I/II and III/IV was detected by RT-qPCR. ${ }^{* *} \mathrm{P}<0.01 \mathrm{vs}$. I/II. (C) RT-qPCR was performed to measure the expression of miR155HG in IOSE80, OVCAR3 and SK-OV-3 cells. ${ }^{* * *} \mathrm{P}<0.001$ vs. IOSE80. miR, microRNA; OC, ovarian cancer; RT-qPCR, reverse transcription-quantitative PCR; FIGO, International Federation of Gynecology and Obstetrics.

miR155HG directly targets miR-155-5p. To confirm the miR155HG mechanism of action in OC development, miR-155-5p was identified as a potential miR155HG target via StarBase (Fig. 3A). The dual-luciferase reporter assay showed that miR-155-5p upregulation evidently attenuated the activity of the WT-miR155HG reporter in OVCAR3 and SK-OV-3 cells ( $\mathrm{P}<0.001$; Fig. 3B). In addition, si-miR155HG-1 transfection markedly enhanced miR-155-5p expression in OVCAR3 and SK-OV-3 cells ( $\mathrm{P}<0.001$; Fig. 3C). In addition, miR-155-5p expression was dramatically inhibited in $\mathrm{OC}$ tissues compared with that in adjacent non-tumor tissues $(\mathrm{P}<0.001$; Fig. 3D). An inverse correlation between miR155HG and miR-155-5p expression was observed in OC tissues (Fig. 3E). miR-155-5p expression was considerably downregulated in OVCAR3 and SK-OV-3 cells compared with that in IOSE80 cells $(\mathrm{P}<0.001$, Fig. 3F).

miR-155-5p elevation impedes OC cell viability, migration and invasion while facilitating apoptosis. To determine the biological function of miR-155-5p in OC, miR-155-5p was enhanced or blocked after miR-155-5p mimic $(\mathrm{P}<0.001)$ or miR-155-5p inhibitor $(\mathrm{P}<0.01)$ transfection in OVCAR3 and SK-OV-3 cells (Fig. 4A). miR-155-5p elevation significantly attenuated the viability of OVCAR3 and SK-OV-3 cells $(\mathrm{P}<0.01$; Fig. 4B). Furthermore, miR-155-5p elevation markedly retarded the migration and invasion of OVCAR3 and 

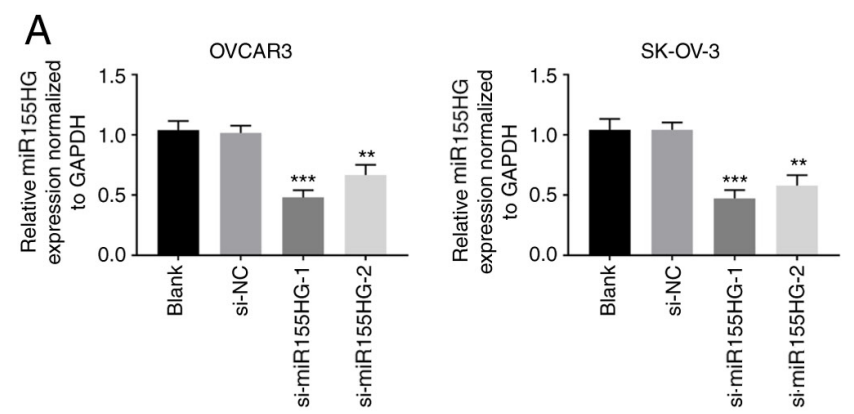

C
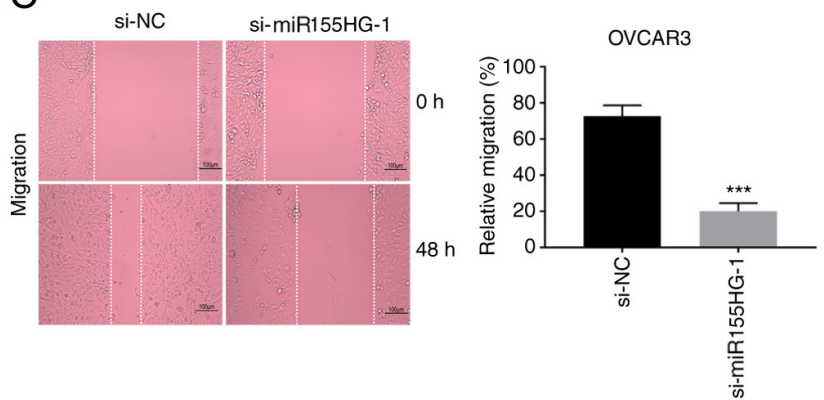

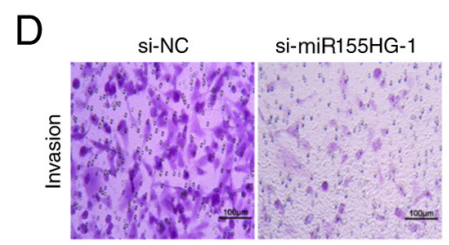

E
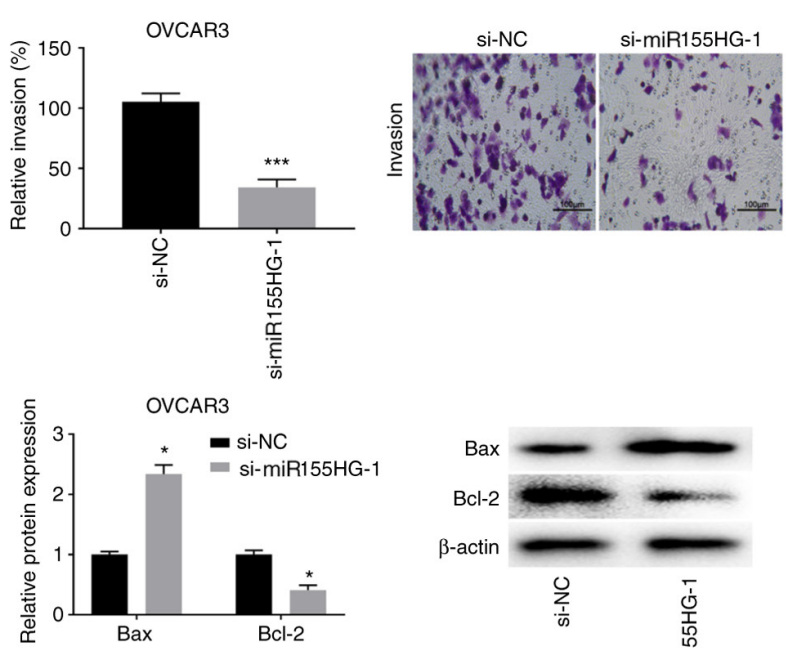
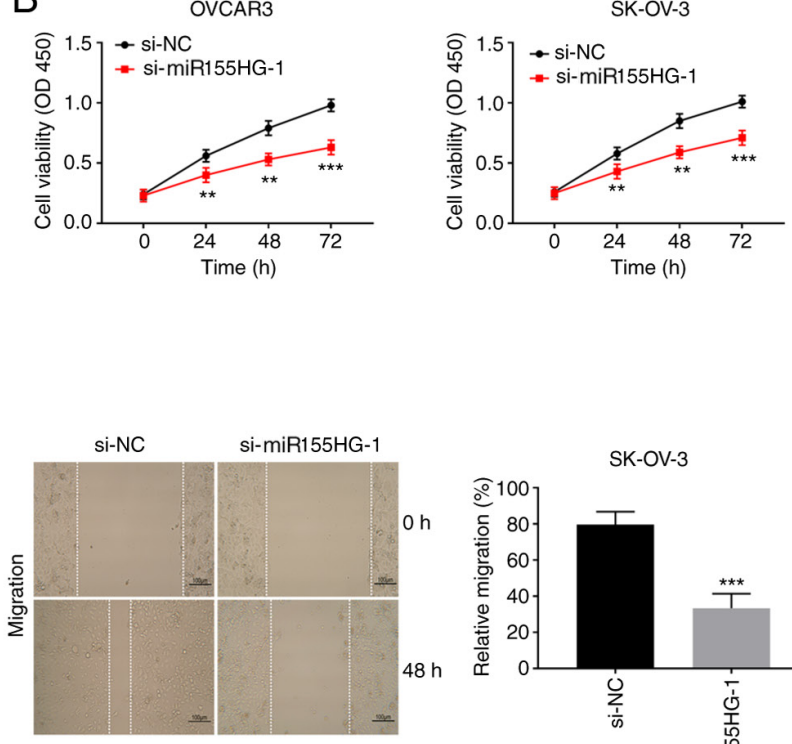

$\mathrm{B}$
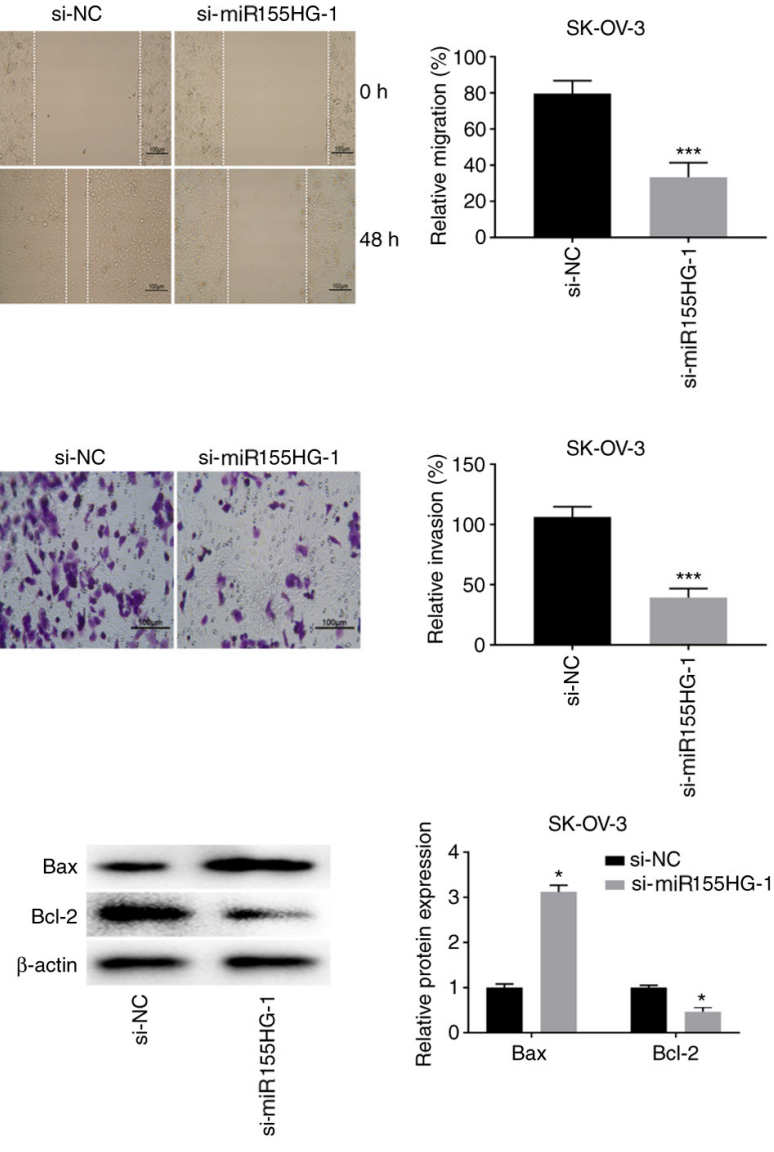

Figure 2. miR155HG silencing restrains the viability, migration and invasion, while promoting apoptosis of OC cells. (A) The transfection efficiency of si-NC, si-miR155HG-1 and si-miR155HG-2 in OVCAR3 and SK-OV-3 cells was measured by reverse transcription-quantitative PCR. ${ }^{* *} \mathrm{P}<0.01$, ${ }^{* * *} \mathrm{P}<0.001$ vs. si-NC. (B) The viability of OVCAR3 and SK-OV-3 cells was assessed by MTT assay. ${ }^{* *} \mathrm{P}<0.01,{ }^{* * *} \mathrm{P}<0.001$ vs. si-NC. The (C) migration and (D) invasion of OVCAR3 and SK-OV-3 cells were analyzed by wound-healing assay and invasion assay. ${ }^{*}{ }^{* *} \mathrm{P}<0.001$ vs. si-NC. Scale bar=100 $\mu \mathrm{m}$; (E) The protein expression of Bax and Bcl-2 in OVCAR3 and SK-OV-3 cells were measured by western blotting. " $\mathrm{P}<0.05$ vs. si-NC. miR, microRNA; OC, ovarian cancer; si, short interfering; $\mathrm{NC}$, negative control; OD, optical density.

SK-OV-3 cells ( $\mathrm{P}<0.001$; Fig. $4 \mathrm{C}$ and $\mathrm{D})$. Overexpression of miR-155-5p not only significantly elevated the Bax protein expression level but also reduced the $\mathrm{Bcl}-2$ protein expression level in OVCAR3 and SK-OV-3 cells $(\mathrm{P}<0.05$; Fig. 4E).

TYRP1 is a target of miR-155-5p. To demonstrate whether TYRP1 is a direct target of miR-155-5p in OC, TargetScan was used to predict the binding site for miR-155-5p on the 3'-UTR of TYRP1 (Fig. 5A). The dual-luciferase reporter assay showed that miR-155-5p elevation clearly hindered the activity of the WT-TYRP1 reporter in OVCAR 3 and SK-OV-3 cells $(\mathrm{P}<0.01$; Fig. 5B). Additionally, miR-155-5p deficiency visibly enhanced TYRP1 expression in OVCAR3 and SK-OV-3 cells $(\mathrm{P}<0.001$;
Fig. 5C). Furthermore, TYRP1 expression was upregulated in OC tissues compared with that in adjacent non-tumor tissues $(\mathrm{P}<0.001$; Fig. 5D). A negative correlation between TYRP1 and miR-155-5p expression (Fig. 5E) and a positive correlation between TYRP1 and miR155HG expression (Fig. 5F) were observed in OC tissues. TYRP1 expression was upregulated in OVCAR3 and SK-OV-3 cells compared with that in IOSE80 cells $(\mathrm{P}<0.001$; Fig. 5G).

miR155HG silencing hampers the malignant biological behavior of OC cells by targeting the miR-155-5p/TYRPI axis. To ascertain whether miR155HG modulates TYRP1 expression by affecting miR-155-5p repression activity, 


\section{A}

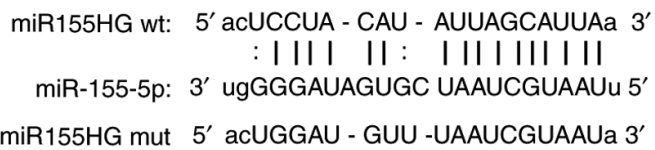

$\mathrm{B}$

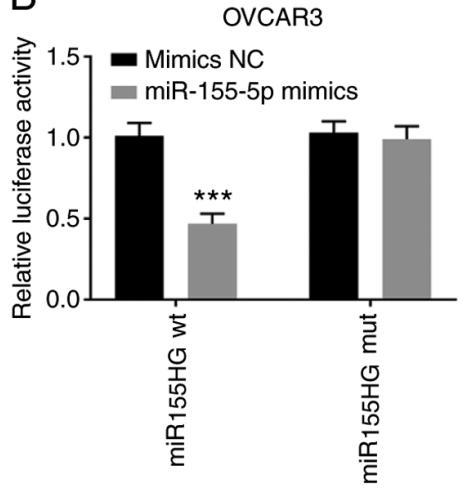

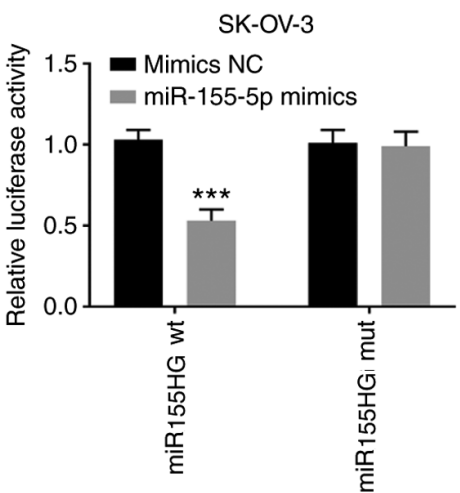

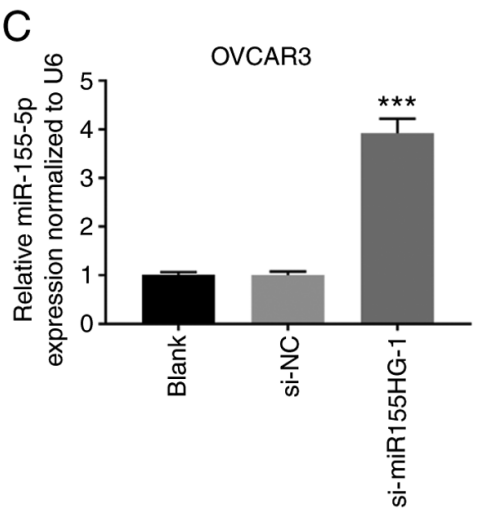

E

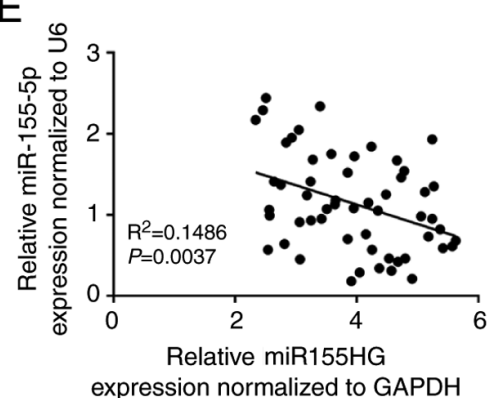

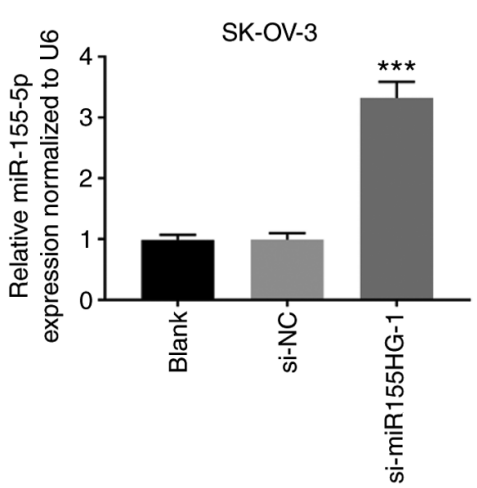

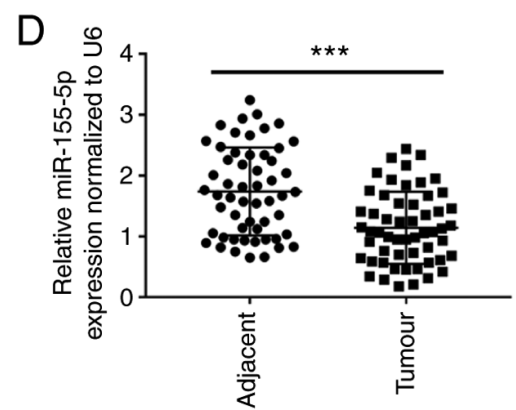

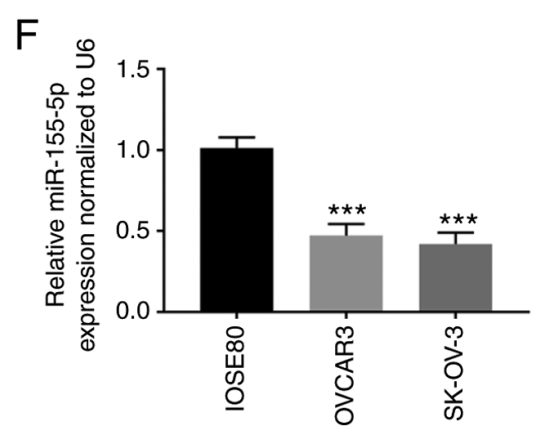

Figure 3. miR155HG directly targets miR-155-5p. (A) StarBase showed the predicted binding site between miR $155 \mathrm{HG}$ and miR-155-5p. (B) Relative luciferase activity in OVCAR3 and SK-OV-3 cells was evaluated by dual-luciferase reporter assay. ${ }^{* * *} \mathrm{P}<0.001$ vs. mimics NC. (C) The expression of miR-155-5p was increased by the transfection of si-miR155HG-1 in OVCAR3 and SK-OV-3 cells. ${ }^{* * *} \mathrm{P}<0.001$ vs. si-NC; (D) RT-qPCR was performed to detect the expression of miR-155-5p in OC tissues and adjacent non-tumor tissues. ${ }^{* * *} \mathrm{P}<0.001$ vs. Adjacent; (E) The expression of miR155HG was negatively correlated with miR-155-5p in OC tissues; (F) The expression of miR-155-5p in IOSE80, OVCAR3 and SK-OV-3 cells was detected by RT-qPCR. ${ }^{* * * *} \mathrm{P}<0.001$ vs. IOSE80. miR, microRNA; NC, negative control; si, short interfering; RT-qPCR, reverse transcription-quantitative PCR; OC, ovarian cancer; wt, wild-type; mut, mutant.

feedback approaches were used, in which the effects of miR155HG silencing were reversed by TYRP1 overexpression or miR-155-5p inhibition. OVCAR3 cells were transiently transfected with pcDNA3.1-NC or pcDNA3.1-TYRP1. The overexpression efficiency of pcDNA3.1-TYRP1 was high in OVCAR3 cells. TYRP1 expression was effectively enhanced following transfection with pcDNA3.1-TYRP1 in OVCAR3 cells $(\mathrm{P}<0.001$; Fig. $6 \mathrm{~A})$. In addition, the protein expression level of TYRP1 was markedly increased in OVCAR3 cells following transfection with pcDNA3.1-TYRP1 $(\mathrm{P}<0.01$; Fig. 6B). As shown in Fig. 6C, miR155HG silencing visibly suppressed TYRP1 expression in OVCAR3 cells $(\mathrm{P}<0.001)$, whereas miR-155-5p deficiency weakened the inhibitory effect of miR155HG silencing on TYRP1 expression $(\mathrm{P}<0.05)$. The feedback approaches showed that TYRP1 elevation or
miR-155-5p deficiency considerably mitigated the inhibitory effects of miR155HG silencing on OVCAR3 cell viability, migration and invasion $(\mathrm{P}<0.01$; Fig. 6D-G). In addition, TYRP1 overexpression or miR-155-5p inhibition markedly weakened the promotive effect of miR155HG silencing on the Bax protein expression level and reversed the reduction effect of miR155HG silencing on the Bcl-2 protein expression level in OVCAR3 cells $(\mathrm{P}<0.05$; Fig. $6 \mathrm{H})$.

\section{Discussion}

It has been documented that the expression of lncRNAs, such as PTAR (28), TP73-AS1 (29) and CCAT1 (30), is increased in OC. In the present study, miR155HG expression was upregulated in OC, suggesting that miR155HG may be 

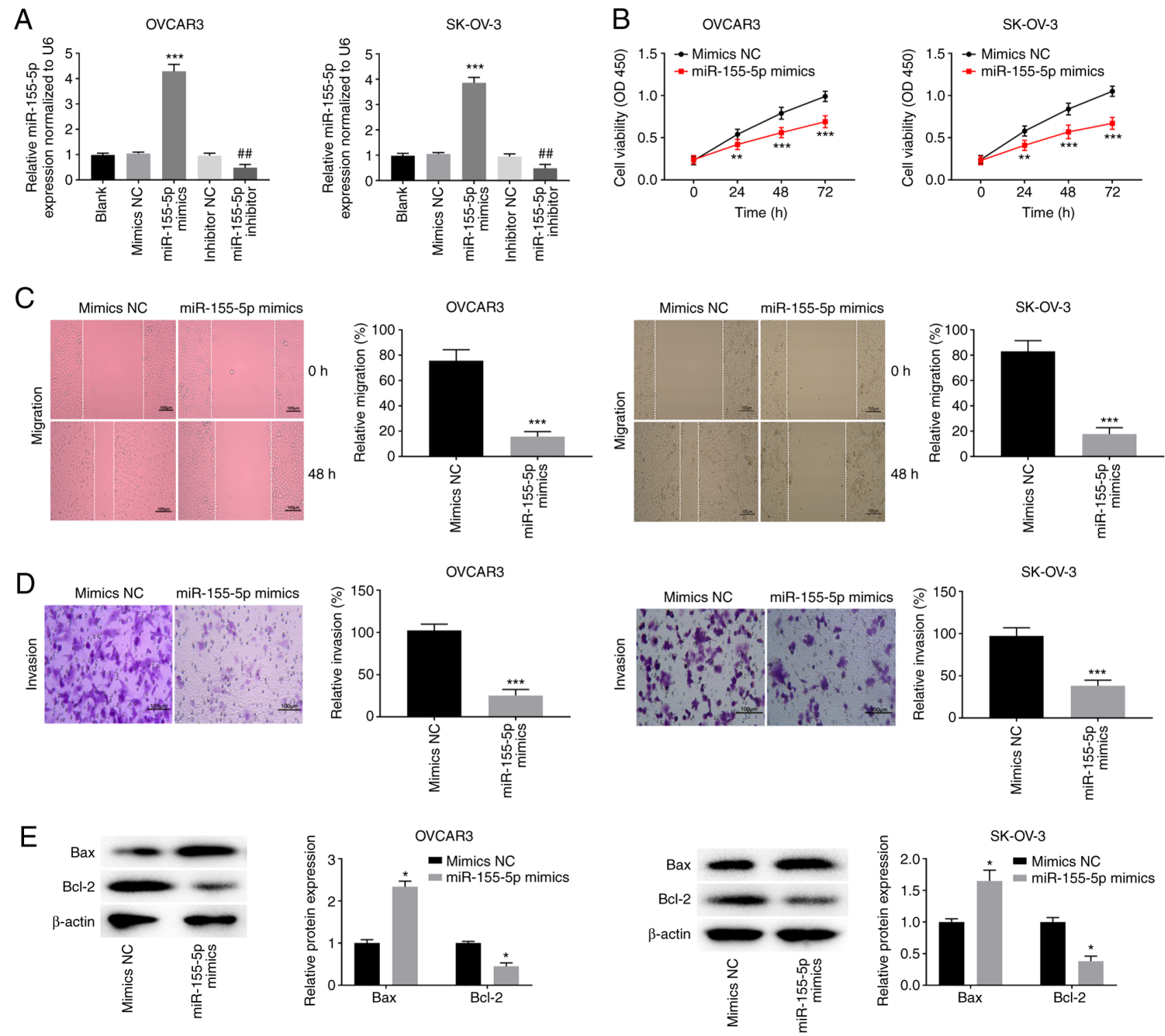

Figure 4. miR-155-5p elevation impedes the viability, migration and invasion while facilitating apoptosis of OC cells. (A) The transfection efficiency of mimics NC, miR-155-5p mimics, inhibitor NC and miR-155-5p inhibitor was evaluated by reverse transcription-quantitative PCR in OVCAR3 and SK-OV-3 cells. ${ }^{* * * *} \mathrm{P}<0.001$ vs. mimics NC, ${ }^{\# \#} \mathrm{P}<0.01$ vs. inhibitor NC; (B) MTT assay were performed after transfected with mimics NC or miR-155-5p mimics in OVCAR3 and SK-OV-3 cells. ${ }^{* *} \mathrm{P}<0.01,{ }^{* * *} \mathrm{P}<0.001$ vs. mimics NC. The effects of miR-155-5p overexpression on the (C) migration and (D) invasion of OVCAR3 and SK-OV-3 cells were assessed. ${ }^{* * * *} \mathrm{P}<0.001$ vs. mimics NC. Scale bar $=100 \mu \mathrm{m}$; (E) Western blotting was performed to detect the protein expression of Bax and Bcl-2 in OVCAR3 and SK-OV-3 cells. "P<0.05 vs. mimics NC. miR, microRNA; OC, ovarian cancer; NC, negative control; si, short interfering; OD, optical density.

an oncogene. In addition, a high level of miR155HG was correlated with FIGO stage in patients with OC. Certain lncRNAs are similar to miR155HG. For instance, high lncRNA PVT1 expression is related to poor prognosis and advanced FIGO stage in patients with OC (5). Overexpression of IncRNA HOTTIP is markedly correlated with advanced FIGO stage in patients with OC (31). Above all, the present study suggested that miR155HG expression may be associated with OC development. Previous studies have demonstrated that miR155HG participates in the malignant biological behavior of diverse cancers $(24,32,33)$. miR $155 \mathrm{HG}$ silencing diminishes cell viability while facilitating cell apoptosis by targeting PTBP1 to restrain glioma development (32). miR155HG knockdown upregulates miR-155-3p and downregulates TP53INP1, thus retarding the biological behavior of non-small cell lung cancer (33). miR155HG downregulation hinders laryngeal squamous cell carcinoma progression by increasing miR-155-5p and reducing SOX10 expression (24). In the present study, miR155HG knockdown attenuated OC cell viability, invasion and migration while promoting OC cell apoptosis, indicating that miR155HG silencing may inhibit the development of OC.

Some lncRNAs serve as competing endogenous RNAs or molecular sponges to regulate miRNAs in OC. For instance, lncRNA EWSAT1 decreases miR-330-5p expression to accelerate OC progression (34). LncRNA CCAT1 exerts a tumor-promoting role in $\mathrm{OC}$ progression by sponging miR-490-3p (35). Notably, lncRNA NORAD induces OC cell proliferation and cell cycle transition by downregulating miR-155-5p (36). In the present study, miR-155-5p was a target of miR155HG and inversely correlated with miR155HG expression, suggesting that miR155HG may influence OC by 


\section{A}

TYRP1 wt: 5'aauaCAAGCAUAUGUUAGCAUUAa 3' | | ||: : | |||||||| miR-155-5p : 3' ugggGAUAGUG -CUAAUCGUAAUu 5' TYRP1 mut : 5'aauaGAUGGUUAUGAAUCGUAAUa 3'
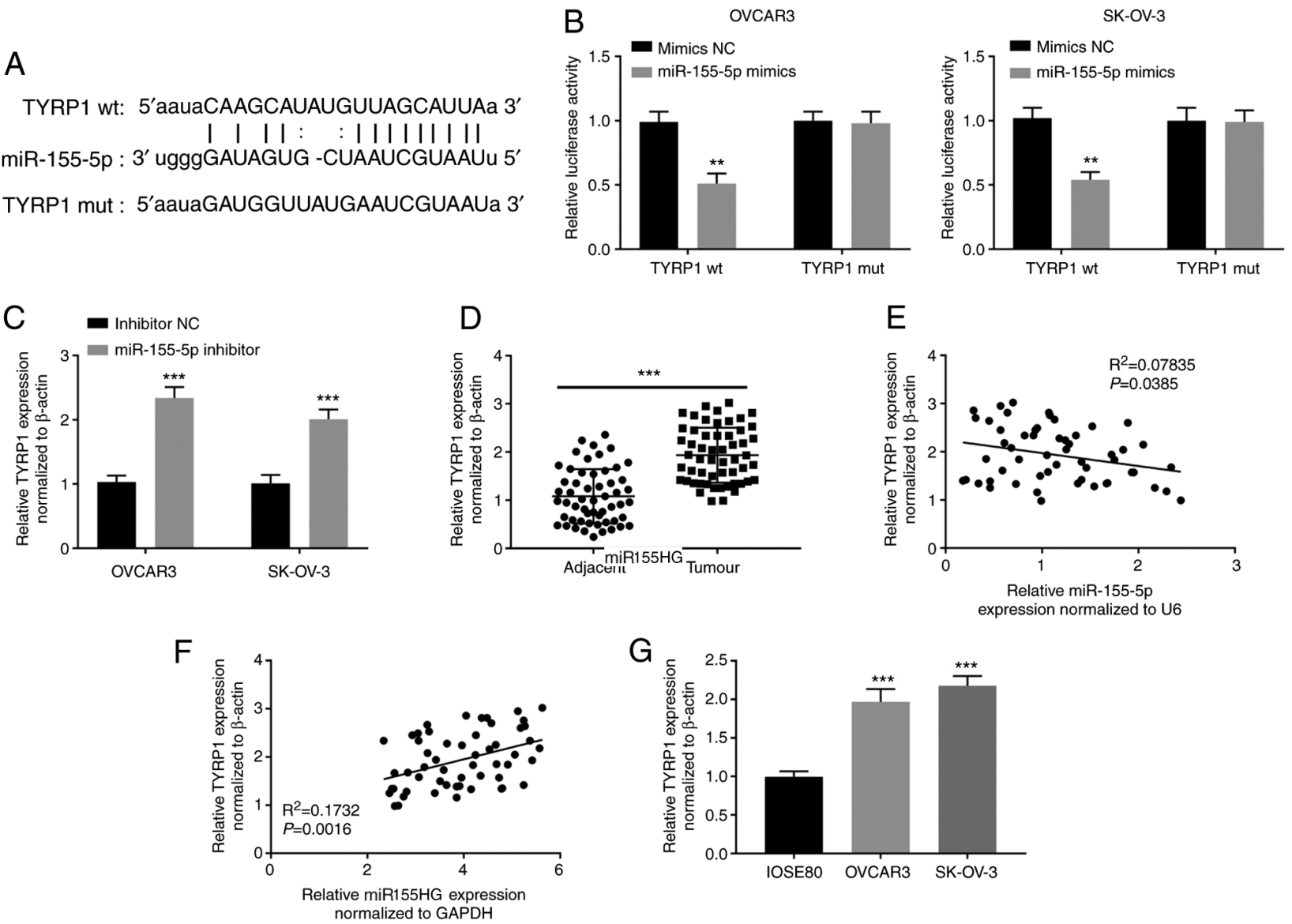

Figure 5. TYRP1 is a target of miR-155-5p. (A) TargetScan displayed the predicted binding site between miR-155-5p and TYRP1. (B) Dual-luciferase reporter assay was performed to measure the relative luciferase activity in OVCAR3 and SK-OV-3 cells. ${ }^{* *} \mathrm{P}<0.01 \mathrm{vs}$. mimics NC. (C) The expression of TYRP1 in OVCAR3 and SK-OV-3 cells was measured by RT-qPCR. ${ }^{* * *} \mathrm{P}<0.001$ vs. inhibitor NC. (D) RT-qPCR was used to detect the expression of TYRP1 in OC tissues and adjacent non-tumor tissues. ${ }^{* * *} \mathrm{P}<0.001$ vs. Adjacent. (E) The expression of TYRP1 was negatively correlated with miR-155-5p in OC tissues. (F) The expression of TYRP1 was positively correlated with miR155HG in OC tissues. (G) RT-qPCR was performed to measure the expression of TYRP1 in IOSE80, OVCAR3 and SK-OV-3 cells. ${ }^{* * *} \mathrm{P}<0.001$ vs. IOSE80. miR, microRNA; NC, negative control; RT-qPCR, reverse transcription-quantitative PCR; OC, ovarian cancer.

regulating miR-155-5p. In fact, miR-155-5p is downregulated and acts as a target of miR $155 \mathrm{HG}$ in some cancers, such as glioma (37), laryngeal squamous cell carcinoma (24) and clear cell renal cell carcinoma (38). In the present study, miR-155-5p was downregulated in OC, indicating that miR-155-5p may be an anti-oncogene. Previous studies have determined that miR-155-5p acts as a tumor suppressor in different cancers. For instance, miR-155-5p decreases CREB1 expression to prevent the malignant behavior of WT cells (39). miR-155-5p attenuates bladder cancer progression by regulating MTGR1 (40). Notably, miR-155-5p overexpression weakens the promotive effects of IncRNA NORAD on OC progression (36). In the present study, miR-155-5p overexpression inhibited the malignant biological behavior of OC cells and miR-155-5p inhibition reversed the anti-tumor effects of miR $155 \mathrm{HG}$ silencing in OC cells. In summary, miR155HG knockdown may suppress the malignant biological behavior of OC cells by upregulating miR-155-5p.

Melanogenic proteins are frequently upregulated in different tumors, such as TYRP1 in melanoma (41) and TYRP2 in glioma (42). Similarly, TYRP1 expression was increased in OC, indicating that TYRP1 may be an oncogene. TYRP1 often acts as an oncogene in certain cancers. TYRP1 attenuates the tumor suppressor activity of miR-16 to facilitate melanoma cell proliferation (43). CXCL1 promotes tumor progression in colon cancer by upregulating TYRP1 (21). Notably, miR-155 downregulates TYRP1 expression to improve the survival of patients with melanoma (22). In the present study, TYRP1 was a target of miR-155-5p and negatively correlated with miR-155-5p. It was hypothesized that miR-155-5p was involved in OC progression by regulating TYRP1. Furthermore, TYRP1 expression was positively associated with miR155HG in OC. Considering the $\mathrm{miR} 155 \mathrm{HG} / \mathrm{miR}-155-5 \mathrm{p}$ targeting relationship, it was hypothesized that miR155HG may enhance TYRP1 expression by inhibiting miR-155-5p in OC. In the present study, feedback approaches revealed that TYRP1 upregulation reversed the suppressed OC cell behaviors caused by miR155HG knockdown. Taken together, the present study suggested that miR155HG knockdown constrained the malignant biological behavior of OC cells by regulating the miR-155-5p/TYRP1 axis.

There were some limitations to the present study. First, the correlation between the expression of miR $155 \mathrm{HG}$ and the survival rate of patients with OC was not analyzed; however, more data about patient survival will be collected in the future. Second, a normal healthy control group was not set up 

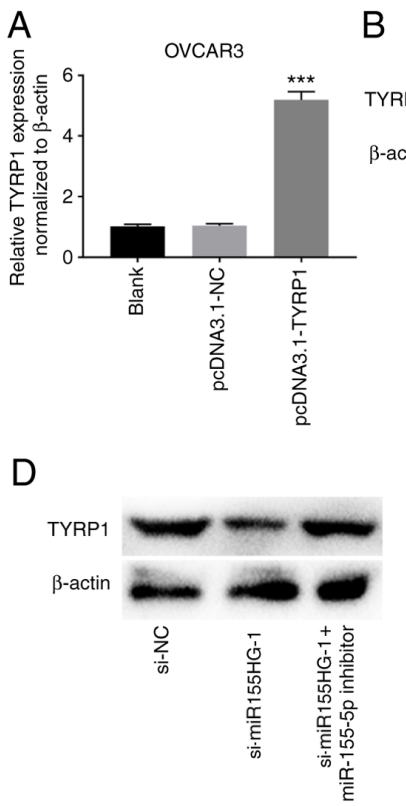

B
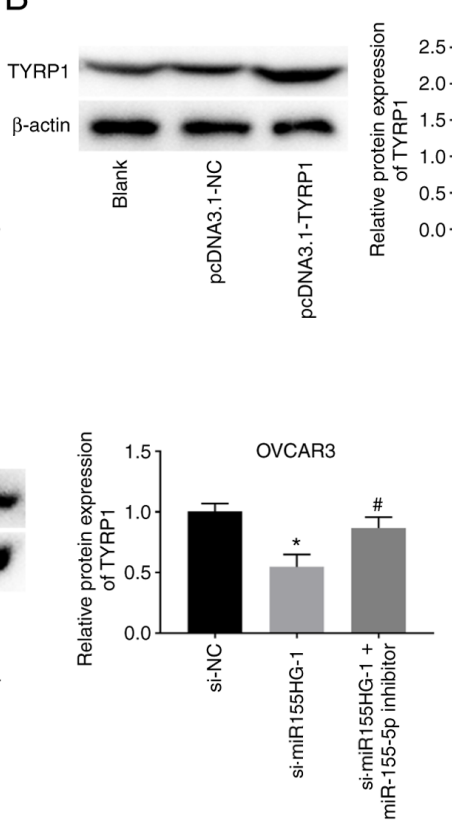

si-miR155HG-1+ si-miR155HG-1+
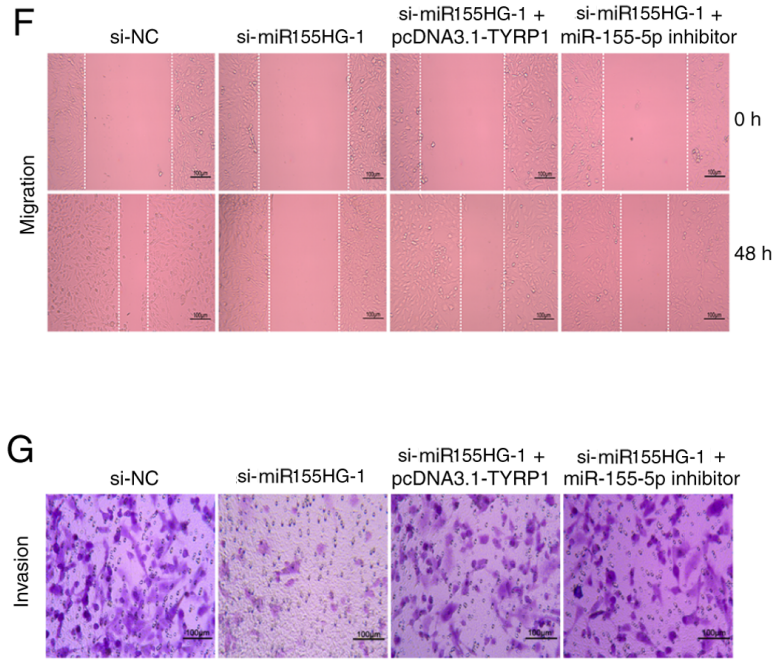

$\mathrm{H}$

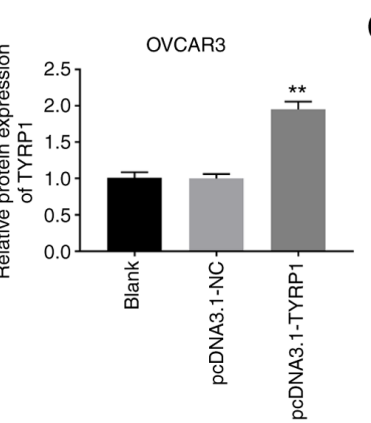

E

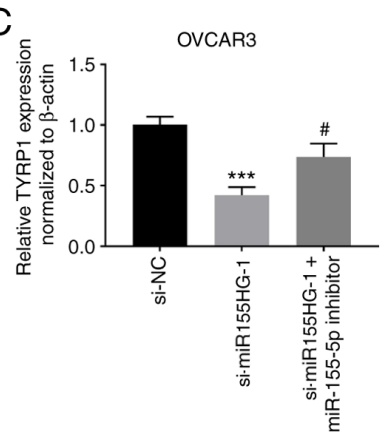

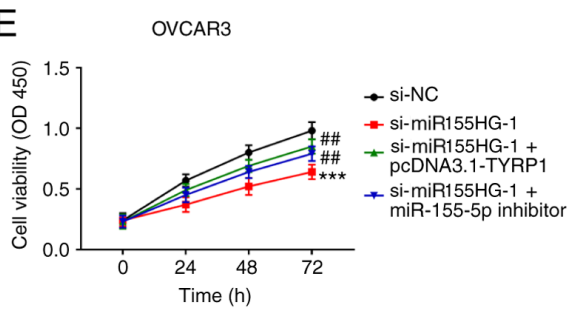
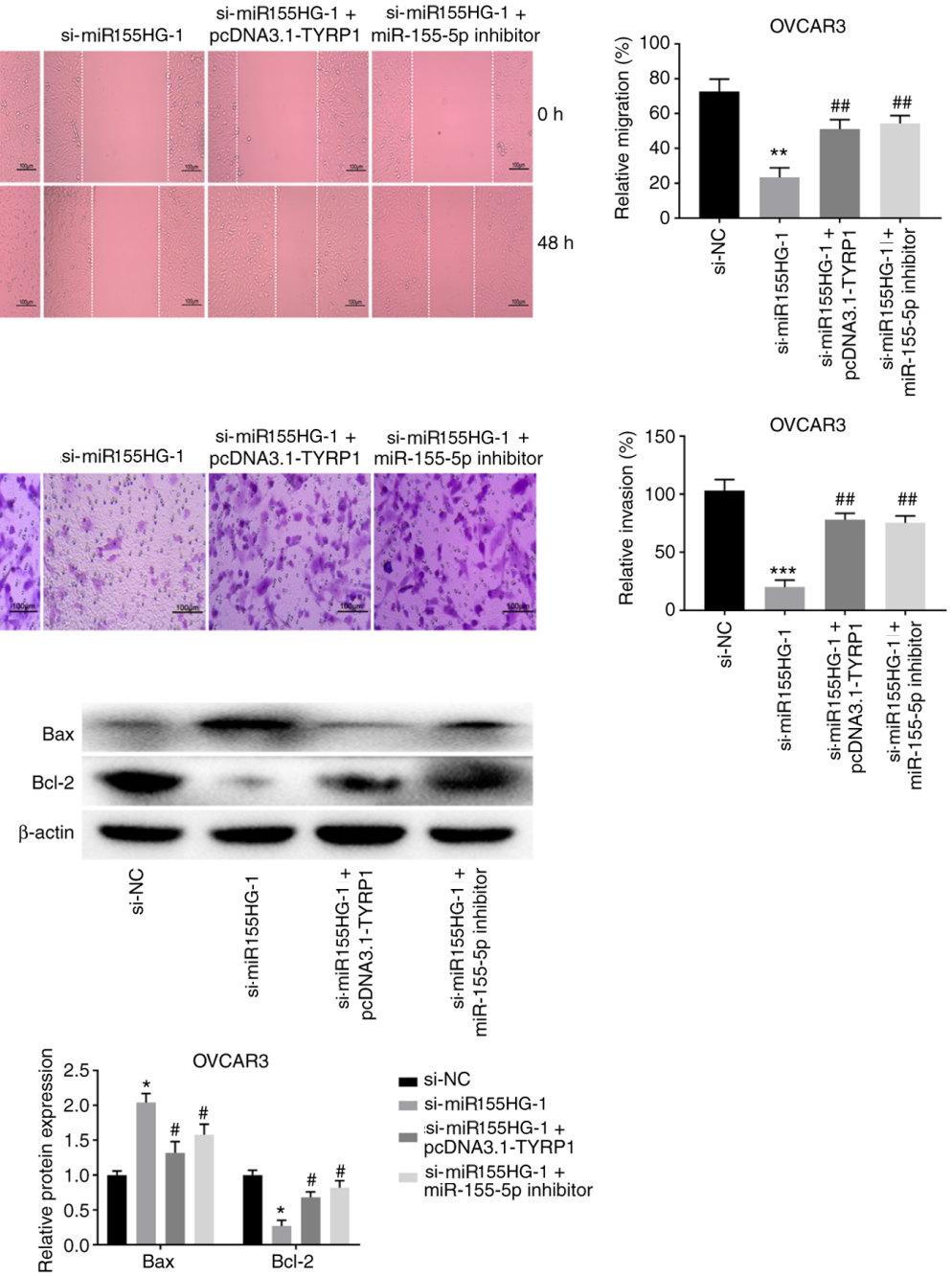

- si-NC

- si-miR155HG-1

si-miR155HG-1+

si-miR155HG-1 +
miR-155-5p inhibito

$\frac{\pi}{\mathbb{2}}$

Figure 6. miR155HG silencing hampers the malignant biological behavior of OC cells by targeting the miR-155-5p/TYRP1 axis. (A) The transfection efficiency of pcDNA3.1-NC and pcDNA3.1-TYRP1 was measured by RT-qPCR in OVCAR3 cells. ${ }^{* * *} \mathrm{P}<0.001$ vs. pcDNA3.1-NC. (B) The protein expression of TYRP1 in OVCAR3 cells was detected by western blotting. ${ }^{* *} \mathrm{P}<0.01$ vs. pcDNA3.1-NC. (C) RT-qPCR was used to detect the expression of TYRP1 in OVCAR3 cells. ${ }^{* * * *} \mathrm{P}<0.001$ vs. si-NC, ${ }^{\text {}} \mathrm{P}<0.05$ vs. si-miR155HG-1. (D) Downregulation of miR-155-5p or upregulation of TYRP1 reversed the inhibitory effects of miR155HG silencing on (E) viability, (F) migration and (G) invasion of OVCAR3 cells. ${ }^{*} \mathrm{P}<0.05,{ }^{* *} \mathrm{P}<0.01,{ }^{* * *} \mathrm{P}<0.001$ vs. si-NC. ${ }^{\#} \mathrm{P}<0.05$, ${ }^{\# \#} \mathrm{P}<0.01$ vs. si-miR155HG-1. Scale bar=100 $\mu \mathrm{m}$. (H) Overexpression of TYRP1 or inhibition of miR-155-5p reversed the effects of miR155HG silencing on the protein expression of Bax and Bcl-2 in OVCAR3 cells. "P<0.05 vs. si-NC; ${ }^{~} \mathrm{P}<0.05$ vs. si-miR155HG-1. miR, microRNA; OC, ovarian cancer; NC, negative control; RT-qPCR, reverse transcription-quantitative PCR; si, short interfering; OD, optical density. 
to compare with the disease group. Third, the present study did not evaluate the effect of radiotherapy or chemotherapy on miR155HG-silenced cells. Fourth, there are a number of other downstream targets of miR155HG that have not yet been evaluated in OC. Fifth, the present study was limited to the cellular level and further in vivo experiments are needed to confirm the role of miR $155 \mathrm{HG}$ in OC.

In summary, miR155HG expression was enhanced in OC. In addition, miR155HG knockdown appeared to exert tumor-repressing roles in OC progression by regulating the miR-155-5p/TYRP1 axis. Thus, the current study may enhance our understanding of the mechanism underlying miR $155 \mathrm{HG}$ in $\mathrm{OC}$ progression.

\section{Acknowledgements}

Not applicable.

\section{Funding}

The present study was financially supported by the Government- Universities Specific Cooperative Scientific Research Project of Nanchong (grant no. 18SXHZ0251).

\section{Availability of data and materials}

The datasets used and/or analyzed during the current study are available from the corresponding author on reasonable request.

\section{Authors' contributions}

AW and LL conceived and designed the present study, analyzed data, performed the experiments and data analyses and wrote the manuscript. CD and XL contributed significantly to analysis and manuscript preparation, performed the experiments and data analyses and revised the manuscript. AW and LL confirm the authenticity of all the raw data. All authors reviewed and approved the final manuscript.

\section{Ethics approval and consent to participate}

The present study was conducted after obtaining ethical approval from the Affiliated Hospital of North Sichuan Medical College [Nanchong, China; approval no. 2020ER (A)066]. Written informed consent was obtained from all participants.

\section{Patient consent for publication}

Not applicable.

\section{Competing interests}

The authors declare that they have no competing interests.

\section{References}

1. Nash Z and Menon U: Ovarian cancer screening: Current status and future directions. Best Pract Res Clin Obstet Gynaecol 65: 32-45, 2020.
2. Nimmagadda S and Penet MF: Ovarian cancer targeted theranostics. Front Oncol 9: 1537, 2020.

3. Chandra A, Pius C, Nabeel M, Nair M, Vishwanatha JK, Ahmad S and Basha R: Ovarian cancer: Current status and strategies for improving therapeutic outcomes. Cancer Med 8: 7018-7031, 2019.

4. Stewart C, Ralyea C and Lockwood S: Ovarian cancer: An integrated review. Semin Oncol Nurs 35: 151-156, 2019.

5. Chen Y, Du H, Bao L and Liu W: LncRNA PVT1 promotes ovarian cancer progression by silencing miR-214. Cancer Biol Med 15: 238-250, 2018.

6. Du W, Feng Z and Sun Q: LncRNA LINC00319 accelerates ovarian cancer progression through miR-423-5p/NACC1 pathway. Biochem Biophys Res Commun 507: 198-202, 2018.

7. Kong FR, Lv YH, Yao HM, Zhang HY, Zhou Y and Liu SE: LncRNA PCAT6 promotes occurrence and development of ovarian cancer by inhibiting PTEN. Eur Rev Med Pharmacol Sci 23: 8230-8238, 2019.

8. Qin Y, Liu X, Pan L, Zhou R and Zhang X: Long noncoding RNA MIR155HG facilitates pancreatic cancer progression through negative regulation of miR-802. J Cell Biochem 120: 17926-17934, 2019.

9. Wu W, Yu T, Wu Y, Tian W, Zhang J and Wang Y: The $\mathrm{miR} 155 \mathrm{HG} / \mathrm{miR}-185 / \mathrm{ANX}$ 2 loop contributes to glioblastoma growth and progression. J Exp Clin Cancer Res 38: 133, 2019.

10. Li N and Zhan X: Identification of clinical trait-related lncRNA and mRNA biomarkers with weighted gene co-expression network analysis as useful tool for personalized medicine in ovarian cancer. EPMA J 10: 273-290, 2019.

11. Xiang $G$ and Cheng $Y$ : miR-126-3p inhibits ovarian cancer proliferation and invasion via targeting PLXNB2. Reprod Biol 18: 218-224, 2018.

12. Lu J, Wang L, Chen W, Wang Y, Zhen S, Chen H, Cheng J, Zhou Y, Li X and Zhao L: miR-603 targeted hexokinase-2 to inhibit the malignancy of ovarian cancer cells. Arch Biochem Biophys 661: 1-9, 2019.

13. Duan Y, Dong Y, Dang R, Hu Z, Yang Y, Hu Y and Cheng J: MiR-122 inhibits epithelial mesenchymal transition by regulating P4HA1 in ovarian cancer cells. Cell Biol Int 42: 1564-1574, 2018.

14. Li S, Zhang T, Zhou X, Du Z, Chen F, Luo J and Liu Q: The tumor suppressor role of miR-155-5p in gastric cancer. Oncol Lett 16: 2709-2714, 2018.

15. Luo X, Dong J, He X, Shen L, Long C, Liu F, Liu X, Lin T, He D and Wei G: MiR-155-5p exerts tumor-suppressing functions in wilms tumor by targeting IGF2 via the PI3K signaling pathway. Biomed Pharmacother 125: 109880, 2020.

16. Ysrafil Y, Astuti I, Anwar SL, Martien R, Sumadi FAN, Wardhana T and Haryana SM: MicroRNA-155-5p diminishes in vitro ovarian cancer cell viability by targeting HIF1 $\alpha$ expression. Adv Pharm Bull 10: 630-637, 2020.

17. Lai X, Wichers HJ, Soler-Lopez M and Dijkstra BW: Structure and function of human tyrosinase and tyrosinase-related proteins. Chemistry 24: 47-55, 2018.

18. Wang-Rodriguez J, Urquidi V, Rivard A and Goodison S: Elevated osteopontin and thrombospondin expression identifies malignant human breast carcinoma but is not indicative of metastatic status. Breast Cancer Res 5: 9, 2003.

19. Udono T, Takahashi K, Yasumoto K, Yoshizawa M, Takeda K, Abe T, Tamai M and Shibahara S: Expression of tyrosinase-related protein 2/DOPAchrome tautomerase in the retinoblastoma. Exp Eye Res 72: 225-234, 2001.

20. El Hajj P, Journe F, Wiedig M, Laios I, Salès F, Galibert MD, Van Kempen LC, Spatz A, Badran B, Larsimont D, et al: Tyrosinase-related protein $1 \mathrm{mRNA}$ expression in lymph node metastases predicts overall survival in high-risk melanoma patients. Br J Cancer 108: 1641-1647, 2013.

21. Hsu YL, Chen YJ, Chang WA, Jian SF, Fan HL, Wang JY and Kuo PL: Interaction between tumor-associated dendritic cells and colon cancer cells contributes to tumor progression via CXCL1. Int J Mol Sci 19: 2427, 2018.

22. El Hajj P, Gilot D, Migault M, Theunis A, van Kempen LC, Salés F, Fayyad-Kazan H, Badran B, Larsimont D, Awada A, et al: SNPs at miR-155 binding sites of TYRP1 explain discrepancy between mRNA and protein and refine TYRP1 prognostic value in melanoma. Br J Cancer 113: 91-98, 2015.

23. Choi JH and Ro JY: The 2020 WHO classification of tumors of soft tissue: Selected changes and new entities. Adv Anat Pathol 28: 44-58, 2021.

24. Cui W, Meng W,Zhao L, Cao H, Chi W and Wang B: TGF- $\beta$-induced long non-coding RNA MIR155HG promotes the progression and EMT of laryngeal squamous cell carcinoma by regulating the miR-155-5p/SOX10 axis. Int J Oncol 54: 2005-2018, 2019. 
25. Li N, Liu $\mathrm{Y}$ and Cai J: LncRNA miR155HG regulates M1/M2 macrophage polarization in chronic obstructive pulmonary disease. Biomed Pharmacother 117: 109015, 2019.

26. Livak KJ and Schmittgen TD: Analysis of relative gene expression data using real-time quantitative PCR and the 2(-Delta Delta C(T)) method. Methods 25: 402-408, 2001.

27. Javadi S, Ganeshan DM, Qayyum A, Iyer RB and Bhosale P: Ovarian cancer, the revised FIGO staging system, and the role of imaging. AJR AM J Roentgenol 206: 1351-1360, 2016.

28. Liang H, Yu T, Han Y, Jiang H, Wang C, You T, Zhao X, Shan H, Yang R, Yang L, et al: LncRNA PTAR promotes EMT and invasion-metastasis in serous ovarian cancer by competitively binding miR-101-3p to regulate ZEB1 expression. Mol Cancer 17: 119, 2018.

29. Wang X, Yang B, She Y and Ye Y: The lncRNA TP73-AS promotes ovarian cancer cell proliferation and metastasis via modulation of MMP2 and MMP9. J Cell Biochem 119: 7790-7799, 2018.

30. Lai XJ and Cheng HF: LncRNA colon cancer-associated transcript 1 (CCAT1) promotes proliferation and metastasis of ovarian cancer via miR-1290. Eur Rev Med Pharmacol Sci 22: 322-328, 2018

31. Zou T, Wang PL, Gao Y and Liang WT: Long noncoding RNA HOTTIP is a significant indicator of ovarian cancer prognosis and enhances cell proliferation and invasion. Cancer Biomark 25: 133-139, 2019

32. He X, Sheng J, Yu W, Wang K, Zhu S and Liu Q: LncRNA MIR155HG promotes temozolomide resistance by activating the wnt/ $\beta$-catenin pathway via binding to PTBP1 in glioma. Cell Mol Neurobiol 11: 1271-1284, 2020.

33. Ren XY, Han YD and Lin Q: Long non-coding RNA MIR155HG knockdown suppresses cell proliferation, migration and invasion in NSCLC by upregulating TP53INP1 directly targeted by miR-155-3p and miR-155-5p. Eur Rev Med Pharmacol Sci 24: 4822-4835, 2020.

34. Fu X, Zhang L, Dan L, Wang K and Xu Y: LncRNA EWSAT1 promotes ovarian cancer progression through targeting miR-330-5p expression. Am J Transl Res 9: 4094-4103, 2017.
35. Mu Y, Li N and Cui YL: The 1ncRNA CCAT1 upregulates TGF $\beta$ R 1 via sponging miR-490-3p to promote TGF $\beta 1$-induced EMT of ovarian cancer cells. Cancer Cell Int 18: 145, 2018

36. Tong L, Ao Y, Zhang H, Wang K, Wang Y and Ma Q: Long noncoding RNA NORAD is upregulated in epithelial ovarian cancer and its downregulation suppressed cancer cell functions by competing with miR-155-5p. Cancer Med 8: 4782-4791, 2019.

37. Wu X, Wang Y, Yu T, Nie E, Hu Q, Wu W, Zhi T, Jiang K, Wang X, Lu X, et al: Blocking MIR155HG/miR-155 axis inhibits mesenchymal transition in glioma. Neuro Oncol 19: 1195-1205, 2017.

38. Tao $\mathrm{M}$, Zhou $\mathrm{Y}$, Jin $\mathrm{Y}$ and $\mathrm{Pu} \mathrm{J}$ : Blocking lncRNA MIR155HG/miR-155-5p/-3p inhibits proliferation, invasion and migration of clear cell renal cell carcinoma. Pathol Res Pract 216: 152803,2020

39. Zhao XS, Han B, Zhao JX, Tao N and Dong CY: miR-155-5p affects Wilms' tumor cell proliferation and apoptosis via targeting CREB1. Eur Rev Med Pharmacol Sci 23: 1030-1037, 2019.

40. Chen L, Yang X, Zhao J, Xiong M, Almaraihah R, Chen Z and Hou T: Circ_0008532 promotes bladder cancer progression by regulation of the miR-155-5p/miR-330-5p/MTGR1 axis. J Exp Clin Cancer Res 39: 94, 2020.

41. Journe F, Id Boufker H, Van Kempen L, Galibert MD, Wiedig M, Salès F, Theunis A, Nonclercq D, Frau A, Laurent G, et al: TYRP1 mRNA expression in melanoma metastases correlates with clinical outcome. Br J Cancer 105: 1726-1732, 2011.

42. Liu G, Khong HT, Wheeler CJ, Yu JS, Black KL and Ying H: Molecular and functional analysis of tyrosinase-related protein (TRP)-2 as a cytotoxic T lymphocyte target in patients with malignant glioma. J Immunother 26: 301-312, 2003.

43. Gilot D, Migault M, Bachelot L, Journé F, Rogiers A, Donnou-Fournet E, Mogha A, Mouchet N, Pinel-Marie ML, Mari B, et al: A non-coding function of TYRP1 mRNA promotes melanoma growth. Nat Cell Biol 19: 1348-1357, 2017.

(7) $($ ) This work is licensed under a Creative Commons Attribution-NonCommercial-NoDerivatives 4.0 International (CC BY-NC-ND 4.0) License. 